\title{
Tubular Adenoma of the Breast: A Case Report
}

\author{
Abu-Rahmeh Zuhair'1, Abu-Rahmeh Maron'2 \\ ${ }^{1}$ Radiology Department, Holy Family Hospital Nazareth, Faculty of Medicine in the Galilee, Bar-Ilan University, \\ Ramat Gan, Israel \\ ${ }^{2}$ Department of Internal Medicine, Holy Family Hospital Nazareth, Faculty of Medicine in the Galilee, Bar-Ilan \\ University, Ramat Gan, Israel \\ Email: zuheir@bezeqint.net
}

Received 29 April 2014; revised 20 May 2014; accepted 5 June 2014

Copyright (C) 2014 by authors and Scientific Research Publishing Inc.

This work is licensed under the Creative Commons Attribution International License (CC BY).

http://creativecommons.org/licenses/by/4.0/

(c) (i) Open Access

\section{Abstract}

Tubular adenomas, also called "pure adenomas", are uncommon benign lesions of the breast which is characterized histologically by a circumscribed mass consisting of prominent lobular proliferation and closely packed small ducts with minimal supporting stroma [1] [2]. These uniformly sized ducts are lined by single layers of epithelium and myoepithelium. They mainly appear in young women, rarely occurring in the elderly [1] [3]-[5]. Tubular adenoma must be differentiated from other benign lesions (fibroadenoma) and from malignant breast cancer (tubular carcinoma). Preoperative diagnosis is often difficult, but the histologic diagnosis of tubular adenoma would be an acceptable diagnosis after needle core biopsy. Both radiologic and cytohistologic examinations performed before surgery may be not diagnostic and surgical excision is necessary in order to reach a precise diagnosis and a definitive treatment. We report a case of tubular adenoma of the breast in a 62-year-old woman preoperatively diagnosed as a breast tubular adenoma by Ultrasuond-guided core biopsy.

\section{Keywords}

Breast, Tubular Adenoma

\section{Case Report}

A 62-year-old woman presented to our Department for a palpable, painless nodule of her left breast, occasionally detected by the patient herself. Her family history was positive for breast cancer, developed by her mother at the age of 55 years. The patient had her first menses at the age of 12 years and reached menopausal status at 55 
years: no parity.

Personal pathologic anamnesis at the time of breast surgeon evaluation, is asymptomatic, and in good general health. On physical examination, a $1 \mathrm{~cm}$ lump located in the internal inferior area of the left breast was detected. Neither skin nor nipple-areola complex alterations were associated with the presence of the nodule.

Diagnostic assessment of the breast lesion was performed, including breast ultrasound, mammography, and core biopsy. Breast ultrasound showed a $10 \mathrm{~mm}$ solid hypoechoic lesion with inhomogeneous echo structure and microcalcifications (Figure 1(a)), and mammographic slides confirmed a high-density nodule with microcalcifications in the left breast, with partially obscured edges (Figure 1(b)). All these clinical and radiologic data were highly suggestive for a malignant lesion. Ultrasound guided core-biopsy was made the result of the pathologic examination was homogeneously tightly packed tubular epithelial component and sparse connective tissue. Actin immunostain highlights a myoepethelial layer (Figure 2).

No surgery excision was done on the patient in periodic control.

\section{Discussion}

Tubular adenoma is a rare, benign lesion of the breast. Few cases are reported in the literature, and these are mainly in young women [1] and have not been associated with oral contraceptive treatment or pregnancy. In $90 \%$ of the cases, these tumors are found in patients younger than 40 years old [6]. Tubular adenoma in postmenopausal women is very rare. According to the classification proposed by Hertel et al. [7] breast adenomas are subdivided into true ademomas, nipple adenomas and fibroadenomas.

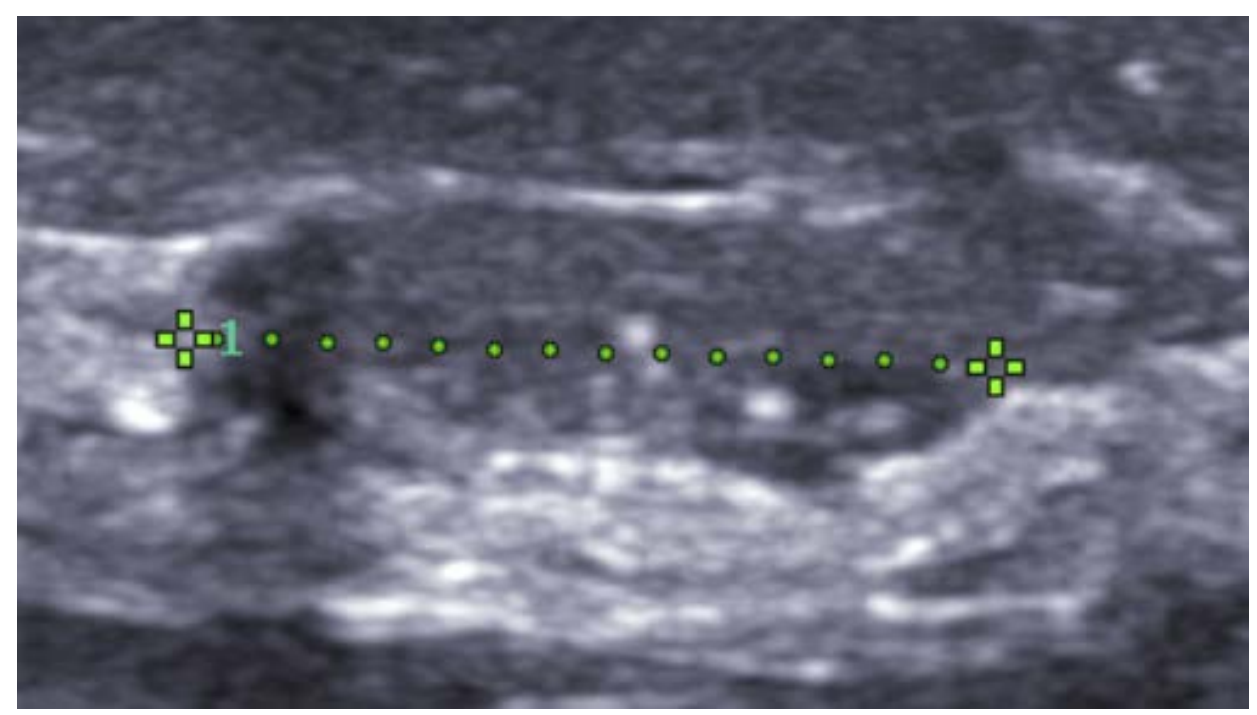

(a)

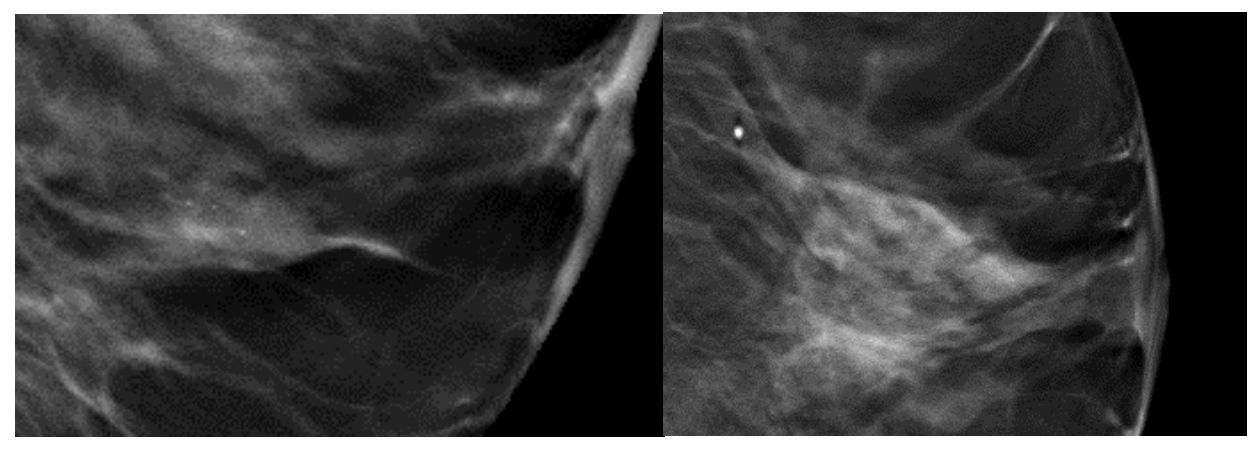

(b)

Figure 1. (a) Breast ultrasound showed a hypoechoic solid lesion with expansive growth pattern and inhomogeneous echo structure, with microcalcifications; (b) Mammographic image of a tubular adenoma as a high-density nodule with compact edge, with microcalcifications. 

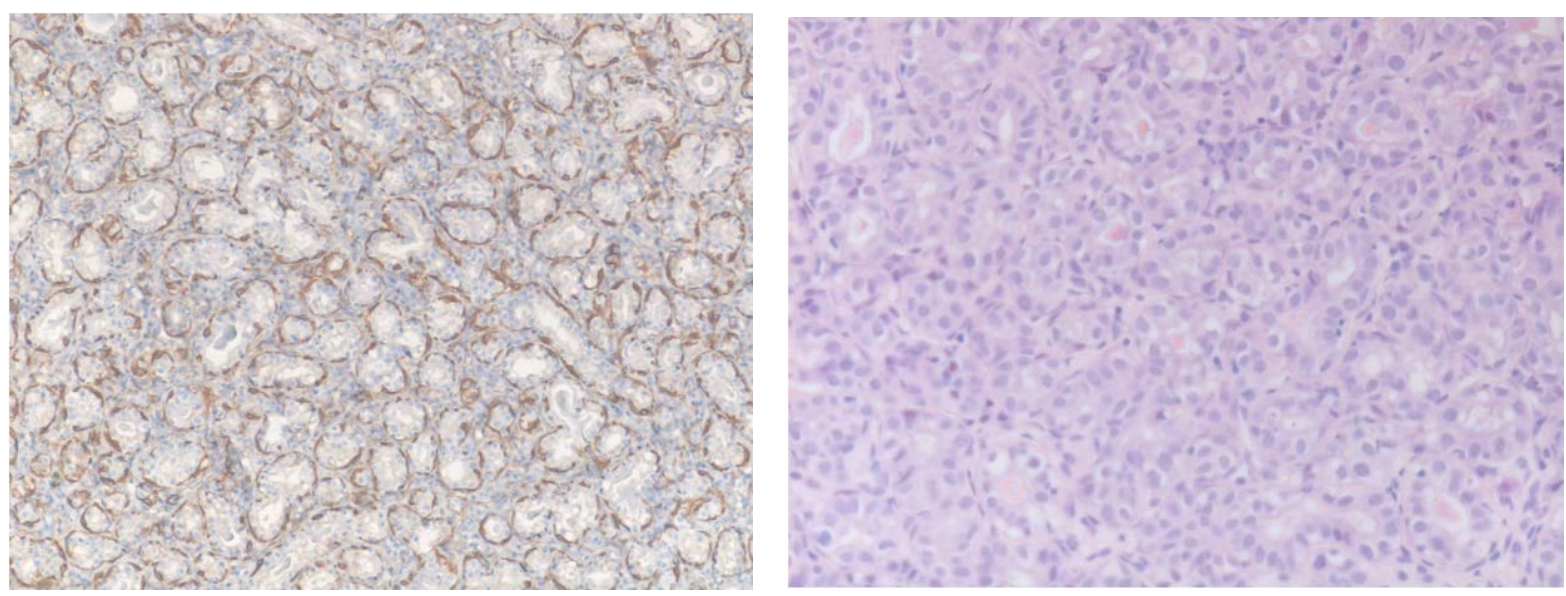

Figure 2. Homogeneously tightly packed tubular epithelial component and sparse connective tissue, Actin immunostain highlights a myoepethelial layer.

Tubular adenoma differs microscopically from fibroadenoma in its histologic and ultrastructural features. Tubular adenomas are characterized by a homogeneously tightly packed tubular or acinar epithelial component and sparse connective tissue, while fibroadenomas present abundant stroma and the epithelial components are characterized by large ducts. The presence of combined tubular adenoma and fibroadenoma accounts for $4 \%$ of all benign lesions [4] and about $11 \%$ of breast adenomas [4] [8].

Clinically tubular adenoma may be asymptomatic and it may be detected occasionally during a screening program (screening mammography) or during a physical examination as a palpable mass. Mammography and ultrasound commonly show non calcified nodules that vary in size; microcalcifications are occasionally described in postmenopausal women [8] [9]. Since it is difficult to differentiate tubular adenoma from malignant breast cancer by clinical and radiological examination [3], core biopsy before surgical excision is usually needed. The case reported here occurred in an elderly woman in whom core biopsy allowed a precise diagnosis of the breast lesion through clinical, radiographic, and pathological evaluations.

Surgical excision is necessary in most cases to obtain the correct diagnosis and is the treatment of choice for this particular histologic type of benign breast lesions. It is important that surgeons keep in mind the existence of this pathologic entity, even in the elderly, in diagnostic assessments of a suspicious breast lesion in order to avoid unnecessary aggressive treatment. Very rare cases of in situ or invasive cancers have been reported to develop in tubular breast adenomas [10].

\section{References}

[1] Rovera, F. and Ferrari, A. (2006) Tubular Adenoma of the Breast in an 84-Year-Old Woman: Report of a Case Simulating Breast Cancer. The Breast Journal, 12, 257-259. http://dx.doi.org/10.1111/j.1075-122X.2006.00250.x

[2] Liu, K., Layfield, L.J. and Krigman, H.R. (1997) Cytologic Features of a Combined Tubular Adenoma and Fibroadenoma of the Breast. Diagnostic Cytopathology, 1, 184-186. http://dx.doi.org/10.1002/(SICI)1097-0339(199702)16:2<184::AID-DC20>3.0.CO;2-H

[3] Salemisa, N.S. (2012) Tubular Adenoma of the Breast: A Rare Presentation and Review of the Literature. Journal of Clinical Medicine Research, 4, 64-67.

[4] Bjerregaard, B. and Kung'u, A. (1992) Benign Breast Lesions in Kenya: A Histological Study. East African Medical Journal, 69, 231-235.

[5] Nishimori, H., Sasaki, M., Hirata, K., et al. (2000) Tubular Adenoma of the Breast in a 73-Year-Old Woman. Breast Cancer, 7, 169-172. http://dx.doi.org/10.1007/BF02967452

[6] Irshad, A., Ackerman, S.J., Pope, T.L., Moses, C.K., Rumboldt, T. and Panzegrau, B. (2008) Rare Breast Lesions: Correlation of Imaging and Histologic Features with WHO Classification. Radiographics, 28, 1399-1414. http://dx.doi.org/10.1148/rg.285075743

[7] Hertel, B.F., Zaloudek, C. and Kempson, R.L. (1976) Breast Adenomas. Cancer, 37, 2891-2905. http://dx.doi.org/10.1002/1097-0142(197606)37:6<2891::AID-CNCR2820370647>3.0.CO;2-P

[8] Stavros, T.A., Thickman, D., Rapp, C.L., et al. (1995) Solid Breast Nodules: Use of Sonography to Distinguish be- 
tween Benign and Malignant Lesions. Radiology, 196, 123-134.

[9] American College of Radiology (1999) Breast Imaging Reporting and Data System. 3rd Edition, American College of Radiology, Reston.

[10] (2003) Tumors of the Breast. In: Tavassoli, F.A. and Devilee, P., Eds., Pathology and Genetics of Tumors of the Breast and Female Genital Organs, World Health Organization Classification of Tumors, Lyon, 9-112. 